\title{
Die Botanisierbüchse
}

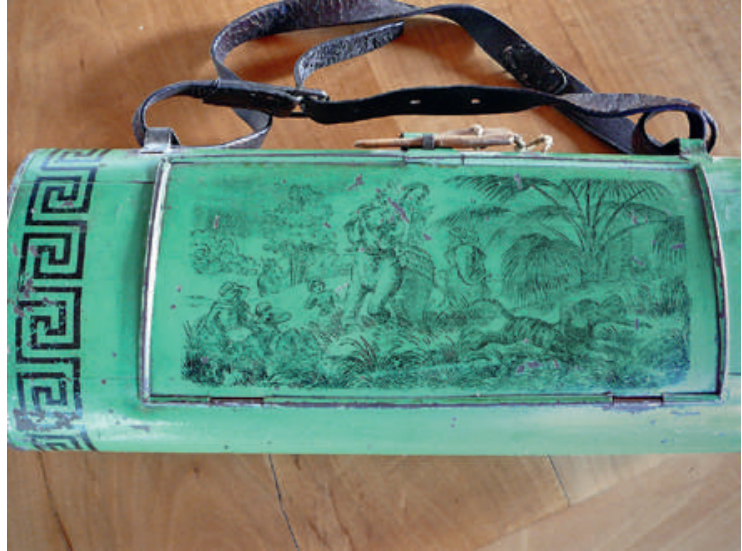

Eine grün lackierte, zylinderförmige Blechtrommel mit Lederriemen, daran eine Klappe mit aufgemalter Tigerjagd und einem Holzstöpsel als Verschluss. Ein Vorfahre mit Wanderstock mag sie getragen haben, ein fleissiger Schüler des grossen Linné. Hat damit sein arzneipflanzliches Wissen erweitert, Flora und Fauna erkundet, beliebig sein Herbarium vergrössert und wohl manchen Käfer mit in die Dose gesperrt. Jetzt liegt das Ding ungenutzt auf dem Regal, mit Büchern, die in Zeiten von E-Books, bald so antiquiert sein werden wie die verstaubte Sammelbüchse.

Zum freien Pflanzeneinsammeln hat Linné eine «Philosophia botanica», einen Wegweiser, geschrieben, ein Büchlein, das auch Goethe als Vademecum bei sich führte. Praktisches wie Kleidung und Hilfsmittel werden darin aufgezählt, von Hundstagen wird abgeraten, Imbiss um zwei Uhr, dann Ruhe bis vier Uhr. Die Einzelbelehrungen erwähnen keine Patentrechte, noch ist alles, was da «kreucht und fleucht», dem Forschenden zu eigen.

Erst mit Louis Pasteurs isolierten Hefen wird 1873 erstmals ein Patent auf Lebewesen erteilt. Wahrscheinlich hätten sich die frühen Botanisierer in die Koalition «Keine Patente auf Saatgut»* eingereiht, die im September 2012 über 70000 Unterschriften dem Präsidenten des Europäischen Parlamentes überreicht hat. In den nächsten Monaten wird das Parlament über ein Einheitspatent beraten. Das Bündnis aus über zweihundert Organisationen, darunter zahlreiche aus der Schweiz, will die Interessen der Züchter, Landwirte und Verbraucher besser schützen. Der Zugang zu Zuchtmaterial und der Verkauf von Saatgut und Nutztieren soll laut Petition nicht durch Patente behindert werden.

Das Europäische Patentamt (EPA) vergibt seit 1989 Patente auf Pflanzen und Tiere. Die Richtlinien von 1998 bestimmen, dass die Erfindung neu sein, gewerblich anwendbar und einen erfinderischen Schritt beinhalten muss. Ausgeschlossen sind Pflanzensorten und Tierrassen, Erfindungen, die in die Keimbahn des Menschen eingreifen, operative und therapeutische Behandlungsmethoden und die Ver- änderung von genetischen Tieridentitäten ohne wesentlichen Nutzen. Viele Verfahren und Kriterien sind nicht eindeutig festgelegt und damit Juristenfutter und Tummelfeld für Lobbyisten aller Art. Das EPA hat schon viele Hunderte Patente auf gentechnisch veränderte Tiere und Pflanzen gewährt und sogar begonnen, auch für reguläre Pflanzen, die nicht gentechnisch verändert sind, Patente zu erteilen. Einerseits sollen Patente geistige Eigentumsrechte schützen und damit die biotechnologische Industrie stimulieren. Andererseits verhindern Patentrechte den Wettbewerb, sie fördern die Monopolisierung durch Firmen wie Monsanto, Syngenta, Bayer BioScience oder Landwirtschaftsministerien einzelner Länder. Präzedenzfälle für umstrittene Verfahren liegen zurzeit vor für Brokkoli, Tomaten, Schweine, Kühe, Sonnenblumen, Melonen und weitere Nutzpflanzen. Zumindest sollen Patente auf konventionelle Züchtungen verhindert werden. Doch Biopatente beschränken sich nicht auf die Landwirtschaft. Die Krebsmaus war das erste transgene Tier mit einem Onkogen im Erbgut, das erst in den USA, dann 2004 in Europa mit der Begründung patentiert wurde, dass der Nutzen für den Menschen schwerer wiege als das moralische Bedenken bezüglich Tierleid. Die ursprünglichen Absichten des Patentschutzes verkehren sich bei grosszügiger Anwendung in ihr Gegenteil. Die Zunahme von Patenten im Bereich der Life Sciences beeinflusst die Auswahl der Forschungsthemen, denn tendenziell sollen sich diese auf patentierfähige, gewinnbringende Ziele ausrichten. Der freie Austausch von Informationen und Grundlagenmaterial wird damit zunehmend wegen Entschädigungsansprüchen behindert.

Diskutiert werden auch entwicklungspolitische und soziale Auswirkungen. Die Botaniker und Herbaristen vergangener Zeiten wären heute mit indigenen Völkern vergleichbar, deren Umwelt und traditionelles Wissen als Rohmaterial für Erfindungen ausgebeutet wird. Sogar die Artenvielfalt steht auf dem Spiel, wenn Monopolisierung und monokulturelle Industrialisierung von Tier- und Pflanzenzucht die angepassten, lokalen Arten verdrängen. Die Entdeckerfreuden gingen rapide zurück. Linné empfahl dem Sammler einen Behälter mit gut schliessendem Deckel und weiter Öffnung für die Hand. Ein Vorhängeschloss war nicht vorgesehen. Die Aussicht auf Biopiraten, die sich in einer fernen Zukunft aus diesen Botanisierbüchsen bedienen, blieb ihm erspart.

Erhard Taverna

.

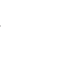

